\title{
Automatic Diagnosis Technology of Lightning Fault in Transmission Line
}

\author{
Chao Yang ${ }^{1}$, Xin Su${ }^{2}$, Haiyan Yuan ${ }^{1}$, Yangyang Liu ${ }^{3, *}$, Wanjie Zhang ${ }^{1}$ and Xin Wang ${ }^{1}$ \\ ${ }^{1}$ State Grid Shandong Electric Power Research Institute \\ ${ }^{2}$ State Grid Jinan Power Supply Company \\ ${ }^{3}$ Shandong Hising Power Tech CO., Ltd \\ ${ }^{*}$ Corresponding author
}

\begin{abstract}
Lightning fault is the main fault of transmission line. Accurate and effective diagnosis of lightning fault can effectively improve the reliability level of transmission line. At present, the determination of lightning strike fault and the location of the lightning strike are determined by manually inquiring the lightning locating system after the lightning strike. In order to improve the real - time determination of lightning fault, the accuracy of lightning strike point positioning and to shorten the outage time due to the lightning strike fault, research on the automatic fault diagnosis technology of the lightning failure of transmission line. According to the lightning fault of the transmission line, the information such as the relevant information of the lightning location system, the GIS information, fault recorder data, the scheduling automation data and the multi-terminal fault location information are used to realize the accurate positioning of the tower and the automatic fault diagnosis function of the transmission line fault. The rapid detection and overhaul of lightning failure is of great significance to the safe and stable operation of power grid.
\end{abstract}

Keywords-lightning locating system; lightning failure; fault location; automatic fault diagnosis

\section{LIGHTNING LOCATION SYSTEM}

High-voltage transmission lines are susceptible to lightning strikes due to their long distance, large span, geographical distribution, and complex meteorological conditions. Transmission lines are more vulnerable to lightning shock due to the diversity of Shandong topography, the province's frequent lightning activity in summer and dense transmission lines. According to China's high-voltage transmission line fault statistics show that the trip faults caused by lightning occupy the total trip failure $40 \%$ to $70 \%$. Lightning failure is the main cause of abnormal transmission of transmission lines and causes a great threat to the safe and stable operation of the grid [1]

Shandong Province put into operation a lightning locating system in 2007. The lightning locating system is a set of automatic, large-scale, high-precision and real-time monitoring system for lightning activity. It can display the Time, position and lightning Value and polarity, lightning current wave waveform, the number of times and each parameter. Lightning positioning system first built 10 detection stations and a central station and built new four stations to upgrade the system and transformation. The detection efficiency of the new generation of lightning positioning system is more than $90 \%$. With the
UHV AC / DC transmission project in China and the rapid development of ultra-high voltage power grid, the requirements of lightning location of ultra-high voltage power grid location are getting higher and higher.

Lightning positioning system, the main technical means of lightning strike location and lightning accident identification, has become an important support platform of reducing lightning faults for China's power grid .The main application of the existing lightning positioning system is through the lightning system to inquire about the lightning situation near the corridor of fault transmission line at the fault time point. Determine manually whether the fault trip is a lightning strike failure by using the knowledge or experience of lightning .The differences between the time of tripping and time of lightning points determine the fault lightning.

\section{THE NECESSITY OF REAL-TIME OF LIGHTNING POINT}

For a long time, determination of lightning failure and the search of lightning strike point are carried out after the lightning failure .The lack of real-time transmission line fault diagnosis function, failed to make a valuable time for the transmission line to quickly resume normal operation [2]. Rapid identification of lightning failure is conducive to the stable operation of the power grid. So the development of lightning fault diagnosis and fault point real-time notification system is very necessary.

Positioning accuracy is an important parameter and system index for characterizing LLS (Lightning Positioning System) performance. The accuracy of the lightning location system is affected by the positioning model, lightning criterion, the propagation delay caused by the site, the error of GPS clock, the distance of detection stations, topography and other factors. When the lightning activity is frequent, it is difficult to determine the lightning which caused the trip fault, because there are many lightning activities near the corridor of fault transmission line at the time of the trip time. Lightning strike near the fault transmission line does not necessarily cause the trip, because the line itself has a certain level of lightning resistance. Lightning in the corridor of the transmission line does not necessarily cause tripping, so it cannot be simply assumed that the trip is caused by the recent lightning strike from the fault line. The lightning strikes that cause the transmission line failure should be analyzed in terms of time consistency or the result of fault recorder. 
Through the real-time communication of the dispatching automation system, the running status of the transmission line is automatically monitored and the tripping time of the transmission line is recorded. If the difference of transmission line trip time and lightning time of the same transmission line time is very small, this fault is lightning strike fault. Start fault diagnosis and fault location function plate and combine the lightning strike system positioning fault location with fault recording distance measurement results to determine the lightning strike fault location. And the results are sent to the relevant personnel through SMS, WeChat and other forms of communication, while the system display the results together with the fault tower on GIS platform based on the Google map.

\section{THE AUTOMATIC DIAGNOSIS PROCESS OF LIGHTNING FAILURE}

Based on EMS trip information, LLS system lightning and tower parameter information of transmission line, lightning real-time monitoring and lightning strike analysis work closely, forming a lightning accident automatic diagnosis and analysis system which can be changed from the passive query mode to active notification mode ${ }^{[3]}$. The Figure I. is the topology of the lightning strike real-time notification system.

From Figure I, we can know the specific process of automatic lightning positioning.

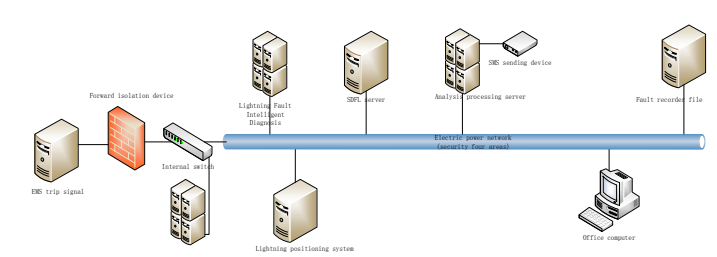

FIGURE I. AUTOMATIC FAULT DIAGNOSIS TOPOLOGY OF TRANSMISSION LINE TRIP LIGHTNING STRIKE

According to the EMS trip information and LLS lightning data, transmission lines, determine the lightning failure by comparing the space and time information of the trip line and the lightning strike point. Calculate the fault location based on double-ended fault data when the transmission line failure is caused by lightning.

Longitude is (Longitude), and West longitude is (Longitude). North latitude is (90-Latitude), and south latitude is (90+Latitude). the coordinates of point $\mathrm{A}$ and point $\mathrm{B}$ are (MLonA, MLatA) and (MLonB, MLatB) after the above treatment. According to the trigonometric function, we can get the formula to calculate the distance between two points. According to the distance between the tower and the fault recorder, the tower number of the faulty transmission line is calculated.

$$
\left\{\begin{array}{l}
C=\sin (\text { MLat } A) * \sin (\text { MLat } B)+\cos (\text { MLat } A) * \cos (\text { MLat } B) * \cos (\text { MlonA }- \text { MLonB }) \\
\text { Dis } \tan c e=R * \arccos (C) * \pi / 180
\end{array}\right.
$$

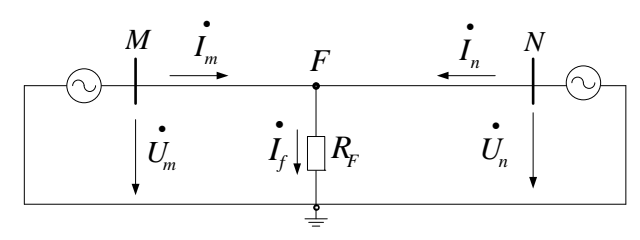

FIGURE II. THE TRANSMISSION LINE HAS FAILED

$$
\left\{\begin{array}{l}
\dot{U}_{m}=\dot{I}_{m} \cdot z \cdot l_{m F}+\dot{I}_{f} R_{f} \\
\dot{I}_{f}=\dot{I}_{m}+\dot{I}_{n}
\end{array}\right.
$$

$$
\left\{\begin{array}{l}
\dot{U}_{m}=U_{m R}+j U_{m I} \\
\dot{I}_{m}=I_{m R}+j I_{m I} \\
\dot{I}_{F}=I_{F R}+j I_{F I} \\
z=R+j X
\end{array}\right.
$$

$$
\begin{gathered}
\left\{\begin{array}{l}
U_{m R}=R_{f} \cdot I_{F R}+\left(R \cdot I_{m R}-X \cdot I_{m I}\right) I_{m F} \\
U_{m I}=R_{f} \cdot I_{F I}+\left(R \cdot I_{m I}+X \cdot I_{m R}\right) l_{m F}
\end{array}\right. \\
I_{m F}=\frac{U_{m R} \cdot I_{F I}-U_{m I} \cdot I_{F R}}{\left(R \cdot I_{m R}-X \cdot I_{m I}\right) I_{F I}-\left(R \cdot I_{m I}-X \cdot I_{m R}\right) I_{F R}}
\end{gathered}
$$

According to the latitude and longitude of the transmission line tower, calculate the distance between each tower. The latitude and longitude of point $\mathrm{A}$ is (LonA, LatA), and the latitude and longitude of point $B$ is (LonB, LatB). East

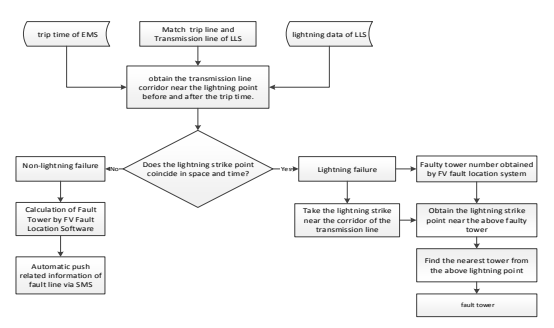

FIGURE III. AUTOMATICALLY DIAGNOSE FAULTY TOWERS CAUSED BY LIGHTNING

In order to realize real-time automatic diagnosis of lightning strikes of transmission lines, real-time diagnosis of lightning failure is realized by connecting the existing information of tripping lines and combining with the existing 
basic data of lightning protection system. The search of lightning strike after the search lightning strike point upgrade to real-time lightning failure automatic diagnosis function to minimize the lightning strike line outage time. The lightning system positioning distance and the combination of the track fault location are used to determine the lightning strike point to improve the accuracy of the lightning strike point, helping Patrolling staff quickly find the fault location and improve power supply reliability.

\section{ANALYSIS OF HISTORICAL LIGHTNING FAULTS}

According to the flow chart, determine whether the fault of transmission line is a lighting strike failure. Use the Lightning positioning system and the trip time of fault time to determine whether it is lightning failure. Describe the lightning strike location process combined with the actual fault.

June 17, 2017 17:34:40, Weihai City, 220kV Du-Lao line lightning strike fault occurred. The actual inspection found fault reason of $220 \mathrm{kV}$ Du-Lao line is \# 8 tower C phase insulator with lightning traces, with a typical lightning discharge phenomenon.
June 17, 2017 17:34, Weihai City, Zhengdu line lightning strike fault occurred. Found the cause of the transmission line failure \# 56 tower C phase insulator with lightning striking traces through lightning location system;

June 24, 2017 12:31, Yantai City, Jin-Zhao II line lightning strike fault occurred. Found that the transmission line failure reason \# 19 tower a phase wire was struck by the actual inspection line. Due to the inaccurate trip time and the relatively dense lightning strike, there is a big error in the fault tower which are inquired by the lightning location system.

In order to improve the efficiency of inspection line, it is necessary to use the new algorithm to improve the accuracy of the fault tower caused by lightning.

First of all, use lightning positioning system to find the lightning strike point before and after the trip time. Select the lightning point, the time of these lightning points before and after five minutes of the trip time. Find the fault lightning strike points near the three transmission lines before and after the trip time.

TABLE I. LIGHTNING MONITORING INFORMATION QUERY RESULTS REPORT(DULAO)

\begin{tabular}{|c|c|c|c|c|c|c|c|}
\hline Serial number & time & longitude & latitude & Current (kA) & Distance (m) & Recent towers & $\begin{array}{l}\text { Fault } \\
\text { tower }\end{array}$ \\
\hline \multirow[t]{2}{*}{1} & 2017-06-02 17:34:41.908 & & & & & & $31 \sim 32$ \\
\hline & 2017-06-02 17:34:41.931 & 122.0828 & 37.4141 & 352.7 & 974 & $31 \sim 32$ & \\
\hline \multicolumn{8}{|l|}{2} \\
\hline & 2017-06-02 17:38:50.874 & 122.0033 & 37.3966 & 37.0 & 554 & 3 & \\
\hline 3 & 2017-06-02 17:38:51.026 & 122.0613 & 37.4408 & 111.4 & 3,767 & 33 & \\
\hline 4 & & 122.0306 & 37.4022 & -24.4 & 704 & $8 \sim 9$ & \\
\hline
\end{tabular}

TABLE II. FAULT TOWER QUERY RESULTS OF ZHENG-DU LINE VIA LIGHTNING LOCATION SYSTEM

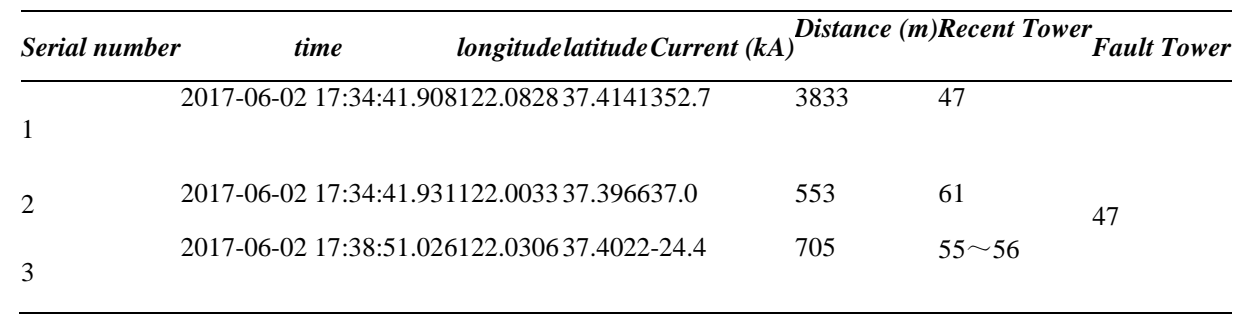


TABLE III. FAULT TOWER QUERY RESULTS OF JIN-ZHAO II LINE VIA LIGHTNING LOCATION SYSTEM

\begin{tabular}{|c|c|c|c|c|}
\hline Serial number & time & $\begin{array}{ccc} & & \text { Distan } \\
\text { longitud latit } & \text { Curr } & \begin{array}{l}\text { ce (m) } \\
\text { ent }\end{array} \\
& \text { ude } & (k A)\end{array}$ & $\begin{array}{l}\text { Rece } \\
\text { Towe } \\
r \\
r\end{array}$ & Tower \\
\hline 1 & $\begin{array}{l}2017-06-24 \\
12: 29: 51.159\end{array}$ & $\begin{array}{c}120.508737 .3-58.2904 \\
889\end{array}$ & $21 \sim 22$ & \multirow{5}{*}{$21 \sim$} \\
\hline 2 & $\begin{array}{l}2017-06-24 \\
12: 31: 13.413\end{array}$ & $\begin{array}{c}120.526937 .3-80.22,901 \\
804\end{array}$ & $21 \sim 22$ & \\
\hline 3 & $\begin{array}{l}2017-06-24 \\
12: 31: 13.457\end{array}$ & $\begin{array}{c}120.512537 .3-34.31,481 \\
841\end{array}$ & $22 \sim 23_{22}$ & \\
\hline 4 & $\begin{array}{l}2017-06-24 \\
12: 31: 13.515\end{array}$ & $\begin{array}{c}120.484537 .4-19.41,810 \\
012\end{array}$ & $22 \sim 23$ & \\
\hline 5 & $\begin{array}{l}\text { 2017-06-24 } \\
12: 31: 13.906\end{array}$ & $\begin{array}{c}120.488037 .4-20.61,519 \\
014\end{array}$ & $22 \sim 23$ & \\
\hline
\end{tabular}

As the trip time is accurate to the minute, the lightning positioning system cannot clear the specific location of the lightning point. Table I, Table II, Table III shows the result of a manual fault in a faulty lightning strike location system. There is a big error between the manual tower and the actual fault tower. At this time, we need to combine the fault recorder positioning system for lightning fault location.

According to the distance between the tower and the fault recorder, the tower number of the faulty transmission line is calculated. The fault distance of Dulao line is $3.22 \mathrm{~km}$; the fault distance of the Zhengdu line is $4.67 \mathrm{~km}$; the fault distance of the Jinzhao line is $15.76 \mathrm{~km}$; According to the distance between the towers of the transmission line, the faulty tower numbers of the three transmission lines are \# 14, \# 60 and \# 17 respectively. Find the nearest lightning strike point from the faulty tower and the lightning strike point causes the transmission line to fail. We need to find the nearest lightning strike point from the initial fault tower.

Figure IV represents the distance between the lightning strike point and the initial faulty tower. Find the nearest lightning strike point from the initial fault tower.

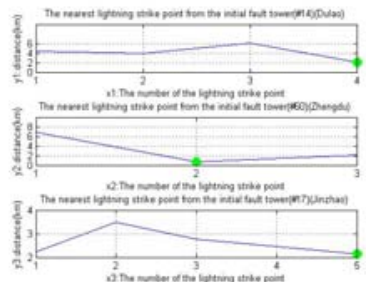

FIGURE IV. THE NEAREST LIGHTNING STRIKE POINT FROM THE INITIAL FAULT TOWER

Find the lightning strike point which caused lightning failure, and then find the tower number of the nearest transmission line from the lightning strike point according to the latitude and longitude of the lightning point and the latitude and longitude of transmission line tower. The calculated tower number of the transmission line is the faulty tower number.

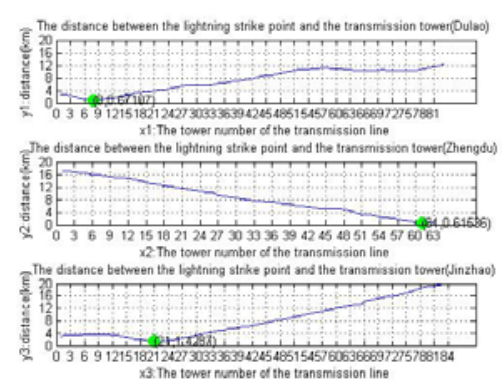

FIGURE V. THE TOWER NUMBER OF THE NEAREST TRANSMISSION LINE FROM THE LIGHTNING STRIKE POINT

Figure $\mathrm{V}$ shows the tower from the nearest lightning strike point and the tower is the fault tower. It can be concluded that the fault location of the new algorithm improves the accuracy of positioning by comparing the traditional positioning results, fault patrol line results and the new algorithm positioning results.

\begin{tabular}{|c|c|c|c|}
\hline $\begin{array}{c}\text { Transmiss } \\
\text { ion line }\end{array}$ & tradition & $\begin{array}{l}\text { patrol } \\
\text { tower }\end{array}$ & $\begin{array}{c}\text { new } \\
\text { algorith } \\
m\end{array}$ \\
\hline $\begin{array}{l}\text { Du-Lao } \\
\text { line }\end{array}$ & $31 \sim 32$ & 8 & 8 \\
\hline $\begin{array}{l}\text { Zheng-du } \\
\text { line }\end{array}$ & 47 & 56 & 61 \\
\hline $\begin{array}{l}\text { Jin-zhao II } \\
\text { line }\end{array}$ & $21 \sim 22$ & 19 & 20 \\
\hline
\end{tabular}

The accuracy of the lightning location system is affected by the positioning model, lightning criterion, the propagation delay caused by the site, the error of GPS clock, the distance of detection stations, topography and other factors. In some areas, the lightning location system cannot accurately locate lightning faults. The use of recorded data for lightning fault calculation is an important means of lightning positioning system, especially when the lightning positioning system failure or data loss occurs. The new algorithm solves the dependence on time and improves the accuracy of lightning positioning.

According to the historical data of lightning failure, find some areas where Lightning Fault location system cannot accurately locate lightning failure. Fault location can be used as an important auxiliary means for lightning locating in this area. 
New algorithm is used for lightning fault location with the combination of lightning positioning system and fault recorder ranging. The new algorithm improves the accuracy of the lightning strike tower and reduces the dependence on time.

\section{REFERENCES}

[1] Chen Jiahong,Zhang Qin,Feng Wanxing, et al. Lighting location system and lightning detection network of China power grid[J]. High Voltage Engineering, 2008, 34(3): 425-431.

[2] Peng Xiangyang,Qin Guanjun,Li Xin,et al.Intelligent trip-out fault diagnosis of overhead transmission line[J].High Voltage Engineering, 2012, 38(8): 1965-1972.

[3] Peng Yong,Wang Zhixin,Chen Jun,et al.lighting fault location and recognition technologies in transmission line[J]. High Voltage Engineering,2010, 36(2): 406-410. 